\title{
Randomised clinical trial of parenteral selenium supplementation in preterm infants
}

\author{
Lynne Daniels, Robert Gibson, Karen Simmer
}

\begin{abstract}
Aim-To determine whether selenium supplementation of parenteral nutrition with $3 \mu \mathrm{g} / \mathrm{kg} / \mathrm{day}$ of selenious acid is safe and effective in improving the selenium status of preterm infants.
\end{abstract}

Methods-Thirty eight preterm infants with mean (SEM) birthweight of 1171 (38) g and gestational age $29(0 \cdot 3)$ weeks were randomly allocated to a nonsupplemented ( $P N-$ selenium, $n=19)$ or supplemented (PN+selenium, $n=19)$ group. The study began at $2 \cdot 8(0 \cdot 2)$ (range $1-5)$ days of age. Term breastfed $(n=23)$ and formula fed $(n=8)$ infants were used as a reference group.

Results-Initially there was no difference between the preterm groups in plasma or erythrocyte selenium or glutathione peroxidase activity. Plasma selenium declined by a mean (SEM) of $-13.3(3 \cdot 2) \mu \mathrm{g} /$ from 28 (4) to 16 (3) $\mu \mathrm{g} / \mathrm{l}$ over the first three weeks in the PN-selenium group, but there was no fall in the supplemented infants and no net change in either group over six weeks. Over six weeks, there was a net decline in erythrocyte selenium of -106 (27) $\mathrm{ng} / \mathrm{g}$ haemoglobin in the PN-selenium group, but no change in the $\mathbf{P N}$ +selenium group, such that at week 6 erythrocyte selenium was lower in the PN-selenium group (401 (17) ng/g haemoglobin) than the $P N+$ selenium group (493 (25) ng/g haemoglobin). Urinary selenium was substantially higher in the PN+selenium group at each week. Initially term and preterm plasma selenium concentrations were similar, but they increased in term breastfed infants $(+17$ (2) $\mu \mathrm{g} / \mathbf{1})$, with both groups of preterm infants having lower plasma selenium concentrations at week 6 compared with term breastfed infants (PN-selenium 22 (3) $\mu \mathrm{g} /$; PN+selenium 23 (4) $\mu$ g/l and term breastfed 49 (2) $\mu \mathrm{g} / 1$ ).

Conclusions-Selenium supplementation of $P N$ at $3 \mathrm{~g} / \mathrm{kg} /$ day prevented depletion in newborns, but was inadequate to achieve selenium concentrations equivalent to those of breastfed term infants. Whether higher doses are more effective remains to be determined, particularly in light of the high urinary selenium secretion in supplemented infants. Selenium supplementation of both parenteral nutrition and formulas is recommended, but the optimal form and dose remain unclear.

(Arch Dis Child 1996; 74: F158-F164)

Keywords: selenium, supplementation, parenteral nutrition, breastfeeding, formula feeds.
The essential trace element selenium is required for the synthesis and activity of the enzyme glutathione peroxidase (GSHPx).This is an important component of antioxidant defence which protects against free radical damage to cells and tissue. ${ }^{1}$ In humans selenium deficiency is poorly defined and rare. Keshan disease, a selenium responsive fatal cardiomyopathy, is seen in pregnant women and children from areas of China with low soil selenium concentrations. ${ }^{2}$ Both biochemical depletion and symptomatic selenium deficiency have been reported in adults and children receiving long term total parenteral nutrition (TPN), ${ }^{1}$ including three cases of fatal cardiomyopathy ${ }^{3}$ and several cases of selenium responsive muscle pain, weakness, and myopathy. ${ }^{4-6}$ Macrocytosis, pseudoalbuminism, and progressive encephalopathy have also been linked to selenium deficiency. ${ }^{78}$ Symptomatic selenium deficiency has been described in adults after as little as 30 days of TPN $^{9}$ and, as in Keshan disease, is typically associated with plasma selenium concentrations in the order of $10 \mu \mathrm{g} / \mathrm{l}^{2} 10$

Symptomatic selenium deficiency has not been described in infants. Newborn plasma concentrations are generally about half those of adults and reflect the wide geographical variation seen in adult populations. ${ }^{1}$ Preterm infants are at risk of selenium depletion due to reduced hepatic stores, ${ }^{11}$ rapid growth, ${ }^{12}$ and poor intake associated with the use of non-supplemented parenteral nutrition and formula. Plasma selenium declines rapidly with postnatal age in preterm infants fed parenterally, ${ }^{13-15}$ which is unlikely to be physiologically appropriate as selenium concentrations increase in healthy term breastfed infants. ${ }^{1617}$ Selenium deficiency compromises antioxidant defence while supplemental oxygen enhances free radical production. ${ }^{18}$ Although animal studies clearly link selenium deficiency with oxygen induced lung damage, 1920 and infants with chronic lung disease (CLD) have clinically relevant selenium depletion, a causative relation has yet to be established. 1315

Although it is recommended that parenteral nutrition for preterm infants be supplemented with $2 \mu \mathrm{g} / \mathrm{kg} /$ day of selenium, ${ }^{10}$ these recommendations have not been evaluated and supplementation is not routine practice in Australia. The purpose of this study was to determine in a blinded, randomised, clinical trial whether parenteral selenium supplementation of preterm infants is safe and effective in improving its concentration in preterm infants, using healthy term infants as a reference group. 


\section{Methods}

A prospective, randomised, clinical trial of parenteral selenium supplementation of preterm infants was conducted at Flinders Medical Centre between November 1992 and April 1994. The study was approved by the Clinical Investigations Committee. Preterm infants weighing less than $2000 \mathrm{~g}$ at birth, without major congenital abnormalities, liver, or renal disease, who were expected to have parenteral nutrition for longer than five days, were eligible for the study, subject to written parental consent.

A stratified randomisation around a birthweight of $1000 \mathrm{~g}$ was undertaken to a non-supplemented group ( $\mathrm{PN}$-selenium) and a group whose nutrition was supplemented with selenium $3 \mathrm{~g} / \mathrm{kg} /$ day (PN+selenium). Supplementation entailed use of a selenious acid solution prepared by the pharmacy in accordance with the formulation of the United States Pharmacopoeial Convention. ${ }^{21}$ The investigators were blinded to which infants were supplemented. A reference group of healthy term infants were enrolled from the postnatal wards during November 1993.

\section{NUTRITION}

Parenteral nutrition, including lipid emulsion, vitamins, and trace elements (zinc, copper, chromium, manganese and iodine) was started within the first 72 hours of life. Analyses indicated that there was no measurable contamination with, or loss of, selenium from standard parenteral nutrition solutions run through a regular giving set over 24 hours. Total parenteral nutrition was ordered and the amount infused was reduced as enteral feeds (mother's expressed breast milk or formula) were introduced in increasing amounts. The selenium content of formula and expressed breast milk were analysed.

In order to document selenium intake from all sources, details of volume and concentration of all fluids consumed or infused were recorded daily. Three and six week preterm data were reported as they correspond, respectively, to the mean days of parenteral nutrition (19 days) and the available reference term data. The percentage of daily energy from expressed breast milk, formula, and parenteral nutrition was calculated for each infant, and averaged over the first three and six weeks of life. Parenteral feeding was defined as $\geqslant 75 \%$ of average daily energy intake from parenteral nutrition; and conversely enteral feeding was described as $\geqslant 25 \%$ energy form expressed breast milk and/or formula. The term infants were divided into two groups (breast or formula) according to the method of feeding at week 6 , but further division of the preterm trial groups into feeding categories produced cell sizes too small for statistical analysis.

COLLECTION OF BLOOD, URINE AND EXPRESSED BREAST MILK

For preterm infants, blood (150-200 $\mu$ l) was taken from arterial line or heel prick within 72 hours of birth (week 0), then weekly until 6 weeks, but only when bloods for clinical care were to be collected. Single void urine samples were collected within 48 hours of the weekly blood sample. Daily samples of expressed breast milk $(1 \mathrm{ml})$ were pooled over each week and stored frozen to give a weekly expressed breast milk sample per infant. Blood was taken from the term infants at day 5 and week 6 when feeding details were recorded.

\section{Processing and storage}

Blood was collected into lithium heparin and plasma, red cells were separated within four hours, and plasma was stored at $-20^{\circ} \mathrm{C}$. Red cells were washed three times with isotonic sodium chloride, and a $50 \%$ saline suspension was prepared on which haemoglobin was determined using the standard cyanmethaemoglobin method with a dedicated haemoglobinometer (Coulter Electronics, Brookvale, Australia). The erythrocyte suspension for selenium assay and a 1 in 20 dilution haemolysate $(0.7 \mathrm{mM}$ mercaptoethanol and $2 \cdot 7 \mathrm{mM}$ neutralised EDTA) for determination of GSHPx activity were stored at $-80^{\circ} \mathrm{C}$. Half of the urine sample was sent fresh for creatinine determination and the remainder was frozen at $-20^{\circ} \mathrm{C}$ for selenium analysis. Expressed breast milk was stored at $-20^{\circ} \mathrm{C}$ and defatted by centrifugation before analysis.

\section{ASSAY PROCEDURES}

Electrothermal atomic absorption was used to determine plasma selenium, using a modified version of the method of Jacobson and Lockitch. ${ }^{22}$ Analysis was carried out on a Varian Spectra AA400 spectrophotometer with deuterium background correction, and a Varian GTA 96 graphite tube atomiser (Varian Techtron, Mulgrave, Victoria). Seronorm Trace Elements Serum (Nycomed Pharmca AS, Oslo, Norway), was repeatedly assayed $(n=219)$ for quality control purposes during each daily run $(n=35)$ and gave a mean recovery of $108 \%$ with an intraday coefficient of variation (CV) of $7 \cdot 2 \%$ and an interday $\mathrm{CV}$ of $4.6 \%$. The overall standard deviation of a single reading on a randomly chosen day was $8.8 \mu \mathrm{g} / 1$ (CV 8.5\%) and the limit of detection was $8 \mu \mathrm{g} / 1$. Plasma selenium was expressed as $\mu \mathrm{g} / \mathrm{l}$ which can be converted to mmol/l by dividing by 79 .

Erythrocyte selenium was analysed ${ }^{23}$ using a Varian Spectra AA40 graphite furnace spectrometer with Zeeman correction (Varian Techtron, Victoria, Mulgrave, Australia). The CV for 10 replicates was $6 \%$, interday variation was $9 \%$, and intraday variation was $6 \%$. Analysis of two bovine blood samples with known selenium content were analysed and gave results within the $95 \%$ confidence limits. Erythrocyte selenium was expressed as $\mathrm{ng} / \mathrm{g}$ haemoglobin of the saline suspension.

The selenium concentration of urine, expressed breast milk, and formula were measured by a modified fluorometric method $^{24}$ with a Hitachi F-2000 flùorescence spectrophotometer (Hitachi Ltd, Tokyo, 
Japan). Seronorm Trace Elements Urine (Nycomed Pharmca AS, Oslo, Norway) was used as a quality control. The mean recovery for Seronorm urine was $92 \%$, with within and between run precisions of $<2 \%$ for Seronorm and pooled neonatal urine. Urinary selenium was expressed as $\mu \mathrm{mol}$ selenium $/ \mathrm{mmol}$ creatinine:this has been shown to be a valid indicator of selenium status. ${ }^{25}$ Creatinine was determined by the routine diagnostic method using a Beckman Synchron CX-3 and colorimetric alkaline picrate method. Standard reference material 1549 bovine non-fat milk powder (National Institute of Standards and Technology, Gaithersburg, USA) was used as quality control material for the milk assay and yielded a CV of $<3 \%$ for within and between run precision.

GSHPx activity was assayed ${ }^{26}$ at $37^{\circ} \mathrm{C}$, with t-butyl hydroperoxide as the substrate and adapted for autoanalysis on the Cobas Bio (Roche, Basle, Switzerland). Enzyme activity was expressed as IU/g haemoglobin of the erythrocyte saline suspension, where IU is the $\mu$ mols of NADPH oxidised per minute. A sample of adult erythrocyte was analysed within each run and used as an internal control, and gave a within run precision of $<5 \%(n=20)$; between run precision was $13 \%(n=7)$. Determinations of this sample also showed that there was no loss of activity with storage at $-80^{\circ} \mathrm{C}$.

\section{STATISTICS}

All analyses were performed using SPSS for Windows 6.0 (SPSS Inc, Chicago, USA). Data were expressed as mean (standard error) unless stated otherwise, and similar alphabetic or numeric superscripts denote a significant difference $(P<0 \cdot 05)$. Differences between groups at time points and within groups over time periods were determined with ANOVA and paired $t$ tests, respectively, using Tukey's LSD post hoc procedure with an $\alpha$ of 0.05 . Log transformation for urinary selenium was required to normalise the data for paired analysis, and the Mann-Whitney $U$ test was used to establish differences in non-transformed urinary selenium data at each week. The $\chi^{2}$ or Fisher's exact test analysis were performed to determine differences in incidence of clinical events between groups.

\section{Results}

Of the 44 preterm infants enrolled, six were subsequently excluded; two died (aged 3 and

Table 1 Clinical and nutritional characteristics of unsupplemented (PN-selenium) and supplemented (PN+selenium) preterm infants

\begin{tabular}{|c|c|c|c|c|}
\hline & \multicolumn{2}{|c|}{$P N-$ selenium $(n=19)$} & \multicolumn{2}{|c|}{$P N+$ selenium $(n=19)$} \\
\hline & Mean (SEM) & Range & Mean (SEM) & Range \\
\hline $\begin{array}{l}\text { Gestational age (weeks) } \\
\text { Birthweight (g) }\end{array}$ & $\begin{array}{r}28(0.5) \\
1211(65)\end{array}$ & $\begin{array}{c}25-31 \\
820-1865\end{array}$ & $\begin{array}{r}29(0.5) \\
1129(42)\end{array}$ & $\begin{array}{c}25-33 \\
796-1534\end{array}$ \\
\hline Intrauterine growth failure & $0 \%{ }^{\star}$ & & $26 \% \%^{\star}$ & \\
\hline Commence enteral feeds (day) $\dagger$ & $11(1)$ & $5-20$ & $12(1)$ & $3-26$ \\
\hline Duration of parenteral nutrition (days) & $19(1)$ & $6-28$ & $18(2)$ & $6-33$ \\
\hline Full enteral feeds (day) $\ddagger$ & $32(3)$ & $7-57$ & $32(3)$ & $14-65$ \\
\hline
\end{tabular}

^Frequency $\% ; P<0.05$, Fischer's exact test. $\dagger>10 \%$ energy from enteral feed for two consecutive days. $\ddagger 100 \%$ of energy from enteral feed for five consecutive days.
11 days), three received $\leqslant$ five days of parenteral nutrition and one inadvertently received a combination of supplemented and unsupplemented parenteral nutrition. A further two infants who died at 42 and 55 days of age were excluded from some clinical variables (age at discharge, days of oxygen). As a result, 19 infants (15 boys, four girls) were included in the control group (PN-selenium) and 19 (eight boys, 11 girls) in the treatment group (PN+selenium). Subjects are described in table 1 . All infants received supplemental oxygen and $92 \%$ were mechanically ventilated. There was no difference between the groups in the use of antenatal steroids $(71 \%$ of all infants), artificial surfactant $(53 \%$ of all infants), or postnatal steroids $(50 \%$ of all infants). Thirty three preterm infants ( $P N-$ selenium, $n=17$, and $P N+$ selenium, $\mathrm{n}=16$ ) received a median of two $(1-10)$ blood transfusions with no difference between the groups (PN-selenium 3.2 (0.7) and PN+selenium $2.8(0.6)$ transfusions). In the healthy term reference group there were 20 male and 12 female infants (mean birthweight 3455 (100) $\mathrm{g}$, length $51(0.5) \mathrm{cm}$, and head circumference $35(0.4) \mathrm{cm})$ with both day 5 and week 6 bloods available.

\section{NUTRITION}

The duration of parenteral nutrition and age at which enteral feeding was started and completely established were similar for both groups (table 1). The $\mathrm{PN}+$ selenium group received a median of 20 (7-60) days of selenium supplementation. At week 3, 47\% $(\mathrm{n}=9) \quad \mathrm{PN}-$ selenium and $21 \% \quad(\mathrm{n}=4)$ $\mathrm{PN}+$ selenium infants were still receiving $>75 \%$ of energy form parenteral nutrition. Sixty three per cent $(n=12)$ of infants in both groups averaged $\geqslant 75 \%$ of energy from parenteral nutrition over the first three weeks of life. By week 4, 85\% of infants were getting a significant proportion of their energy $(\geqslant 25 \%)$ from enteral feeding, and by week 6 this was the case for all but one infant.

There was no difference between the groups in the median percentage of daily energy intake averaged over the first three weeks from expressed breast milk $(10 \%)$, formula $(7 \%)$, or parenteral nutrition $(82 \%)$. Over the first six weeks the proportion of energy from expressed breast milk was $23 \%$, formula $24 \%$, and parenteral nutrition $55 \%$. There were no differences between the groups in mean average daily protein and energy intakes or weight gain over the first six weeks, the latter ranging between 11 and $18 \mathrm{~g} / \mathrm{kg} /$ day after the first week.

The mean selenium concentration of pooled expressed breast milk was $16(0.4) \mu \mathrm{g} / 1$ ( $n=173$, weekly samples from 29 infants). The selenium content of formulas ranged from 2.9-9.5 $\mu \mathrm{g} / 1$. Over the first three weeks the total selenium intake in the $\mathrm{PN}$-selenium group was $0.41(0.07) \mu \mathrm{g} / \mathrm{kg} /$ day compared with 2.06 $(0.12) \mu \mathrm{g} / \mathrm{kg} / \mathrm{day}$ in the $\mathrm{PN}+$ selenium group $(P<0.001)$ and during the first 6 weeks, this was $0.92(0.09) \mu \mathrm{g} / \mathrm{kg} /$ day and $2.04(0.09)$ $\mu \mathrm{g} / \mathrm{kg} /$ day, respectively $(\mathrm{P}<0 \cdot 001)$. 


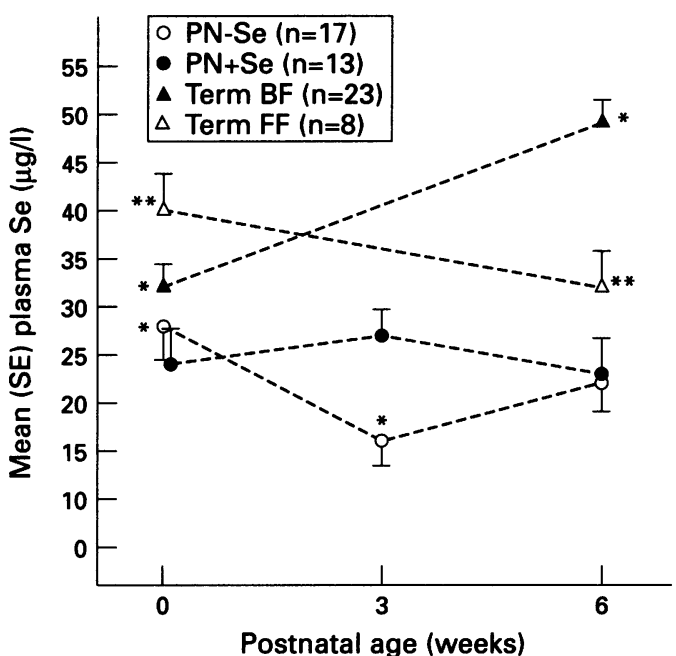

Figure 1 Changes in mean plasma selenium over first six weeks of life in unsupplemented (PN-selenium) and supplemented ( $P N+$ selenium) preterm infants compared with term breastfed and formula fed infants.

\section{INDICATORS OF SELENIUM STATUS}

Changes over the first three weeks

Initially there was no difference between the preterm groups in plasma or erythrocyte selenium or GSHPx activity. Over the first three weeks of life, while the infants were receiving a median of $82 \%$ of daily energy from parenteral nutrition, plasma selenium declined in the $\mathrm{PN}$ - selenium group by -13.3 (3.2) $\mu \mathrm{g} / 1$ from 28 (3) $\mu \mathrm{g} / \mathrm{l}$ at week 0 to 16 (3) $\mu \mathrm{g} / 1$ at week $3(P=0.001, n=17)$, but was maintained in the $\mathrm{PN}+$ selenium group at 26 (3) $\mu \mathrm{g} / 1$ to 27 (3) $\mu \mathrm{g} / \mathrm{l}$ ) (fig 1). At week 3 plasma selenium was significantly lower $(P=0.026)$ in the $P N-$ selenium group. For the small subset of infants who were almost completely parenterally fed $(\geqslant 75 \%$ energy for each of the first three weeks), plasma selenium declined to 11 (3) $\mu \mathrm{g} / 1$ at week 3 in the $\mathrm{PN}$-selenium group $(\mathrm{P}=0.029, \mathrm{n}=5)$ which was significantly lower than the $\mathrm{PN}+$ selenium week 3 concentration ( 34 (5) $\mu \mathrm{g} / \mathrm{l}, \mathrm{n}=5$, $\mathrm{P}=0.009$ ).

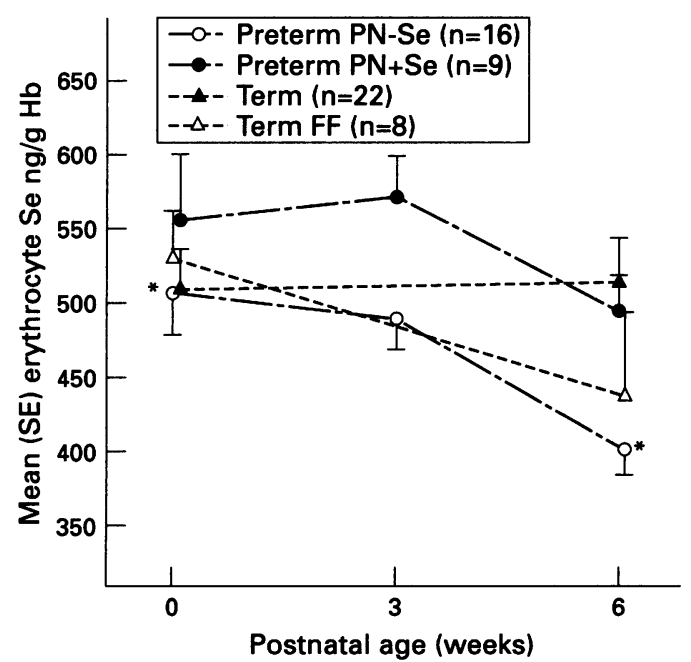

Figure 2 Changes in mean erythrocyte selenium over the first six weeks of life in unsupplemented (PN-selenium) and supplemented (PN+selenium) preterm infants compared with breastfed and formula fed term infants.
When all preterm infants were considered, GSHPx activity increased by $+0.20(0.09)$ IU/g haemoglobin in the $\mathrm{PN}$-selenium group $(1.02(0.08)$ to $1.22(0.09) \mathrm{IU} / \mathrm{g}, \mathrm{n}=16$, $P=0.042$ ), but there was no change in the $\mathrm{PN}+$ selenium group $(1.10(0.09)$ to 1.19 $(0.08) \mathrm{IU} / \mathrm{g}$ haemoglobin, $\mathrm{n}=14, \mathrm{P}=0.264)$. Week 3 values were not significantly different for either group. There was no change in erythrocyte selenium in either group over the first three weeks (fig 2). Plasma concentrations of $\leqslant 10 \mu \mathrm{g} / \mathrm{l}$, which are generally associated with symptomatic deficiency, were more frequent in the $\mathrm{PN}$-selenium than the $\mathrm{PN}+$ selenium group over the first three weeks ( $24 \%$ vs $13 \%$ of measurements, respectively).

\section{Changes over the first 6 weeks}

Changes in plasma selenium over the first six weeks for both term and preterm infants are shown in fig 1. Plasma selenium increased in the term breastfed infants $(P=0.001, n=23)$ but declined in the term formula fed infants $(P=0.039, n=8)$. Despite the differences at three weeks there was no significant net change over six weeks in either preterm group. The comparatively higher initial term plasma selenium in the formula fed group was not a significant covariate for selenium concentrations at week 6. Erythrocyte selenium fell in the $\mathrm{PN}$-selenium group between week 0 and week $6(506$ (28) ng/g haemoglobin to 401 (17) ng/g, $\mathrm{n}=16, \mathrm{P}=0.001$ ), but there was no significant net decline in the other groups (fig 2). In contrast there was a net increase over the first six weeks in GSHPx activity in the PN-selenium group $(1.08(0.10)$ to $1.37(0.08) \mathrm{IU} / \mathrm{g}$ haemoglobin, $n=16, P=0 \cdot 20$ ), but not in any of the other groups. The mean differences between week 0 and week 6 for each group are shown in table 2 . At week 6, both preterm groups and the formula fed term infants had plasma selenium concentrations significantly below those of the term breastfed group ( $P<0.001)$ (fig 1). There was no difference in GSHPx activity between the groups at week 6 and the difference in erythrocyte selenium at week 6 failed to reach significance $(P=0.056)$. The relative ranking can be seen in fig 2 .

The amount of urinary selenium excreted was substantially higher in the $\mathrm{PN}+$ selenium group at each of the first six weeks (fig 3 ). There was a net decline of $-0.05(0.01)$ and $-0.08(0.03) \mu \mathrm{mol} / \mathrm{mmol}$ creatinine in urinary selenium between weeks 1 and 6 in the $\mathrm{PN}$-selenium $\quad(\mathrm{P}=0.004, \quad \mathrm{n}=13) \quad$ and $\mathrm{PN}+$ selenium $(\mathrm{P}=0.037, \mathrm{n}=11)$ groups, respectively. Log urinary selenium at week 3 was associated with plasma selenium at week 3 $(\mathrm{r}=0.36, \quad \mathrm{P}<0.001, \mathrm{n}=24)$ and selenium intake over the first three weeks $(r=0.61$, $\mathrm{n}=35, \mathrm{P}<0.001$ ), but there were no significant correlations at week 6 .

CLINICAL OUTCOME CHARACTERISTICS OF NONSUPPLEMENTED AND SUPPLEMENTED INFANTS

The incidence of CLD, defined as oxygen requirement at 28 days and $x$-ray changes, was 
Table 2 Mean (SEM) net differences in indicators of selenium concentration between weeks 0 and 6 for unsupplemented and supplemented preterm and breastfed and formula fed term infants

\begin{tabular}{|c|c|c|c|c|}
\hline & \multicolumn{2}{|l|}{ Preterm } & \multicolumn{2}{|l|}{ Term } \\
\hline & $P N-$ selenium & $P N+$ selenium & Breastfed & Formula fed \\
\hline $\begin{array}{l}\text { Plasma selenium } \\
\mu \mathrm{g} / \mathrm{l} \\
\mathrm{RBC} \text { selenium } \\
\text { ng/g haemoglobin } \\
\text { GSHPx } \\
\text { IU/g haemoglobin }\end{array}$ & $\begin{array}{c}-6.5(4 \cdot 3)^{a} \\
(n=16) \\
-106(27) \\
(n=19) \\
0.29(0.11)^{d} \\
(n=16)\end{array}$ & $\begin{array}{l}-1 \cdot 2(5 \cdot 7)^{\mathrm{b}} \\
(\mathrm{n}=13) \\
-61(48) \\
(\mathrm{n}=9) \\
0 \cdot 05(0 \cdot 14) \\
(\mathrm{n}=8)\end{array}$ & $\begin{array}{l}+16 \cdot 8(2 \cdot 3)^{\mathrm{abc}} \\
(\mathrm{n}=23) \\
3(32) \\
(\mathrm{n}=22) \\
0 \cdot 11(0 \cdot 10) \\
(\mathrm{n}=23)\end{array}$ & $\begin{array}{l}-8 \cdot 0(3 \cdot 2)^{\mathrm{c}} \\
(\mathrm{n}=8) \\
-93(59) \\
(\mathrm{n}=8) \\
-0 \cdot 29(0 \cdot 18)^{\mathrm{d}} \\
(\mathrm{n}=8)\end{array}$ \\
\hline
\end{tabular}

abc ANOVA, $P<0.0001$; similar superscripts are significantly different $(P<0.05)$ on posthoc testing.

${ }^{d}$ ANOVA indicates differences between groups $(P<0.05)$, but no pairwise group differences on posthoc testing. weeks, by week 6 , once full enteral feeding was established, the groups had very similar plasma selenium concentrations. In contrast, differences in erythrocyte selenium concentrations were evident at six weeks but not in the first three weeks, which confirms that plasma selenium is a shorter term indicator of status when compared with erythrocyte selenium. ${ }^{27}$

Huston et al ${ }^{8}$ showed that parenteral nutrition supplementation of infants (birthweight $<1000 \mathrm{~g}$ ) with $1.5 \mu \mathrm{g} / \mathrm{kg} /$ day of selenious acid ameliorated, but did not prevent, the decline in plasma selenium seen in the control group. Despite initial serum selenium concentrations about twice those of Adelaide preterm infants, a similar pattern of change in plasma selenium was seen and, consistent with our study, the gains achieved by supplemented parenteral nutrition were not maintained once enteral feeding was established. Higher newborn plasma concentrations do not protect against a decline in plasma selenium with postnatal age, but infants with lower newborn concentrations may be at greater risk of severe biochemical depletion. Indeed, plasma selenium concentrations for some infants in our study were similar to those reported in areas with Keshan disease. $^{2}$

The results suggest that, although parenteral nutrition supplementation at $3 \mu \mathrm{g} / \mathrm{kg} /$ day prevents depletion of selenium in newborns, it is inadequate to achieve a concentration equal to that of term breastfed infants. A more appropriate reference group for selenium concentrations in preterm infants may be healthy infants of comparable gestational age fed expressed breast milk from birth, but these data are unavailable as full enteral feeding is rarely tolerated, particularly in very low birthweight infants. There is no evidence to suggest that an increase in plasma selenium concentrations similar to that seen in breastfed term infants is inappropriate in preterm infants, and term cord plasma selenium concentrations, which were similar to week 6 term concentrations, ${ }^{17}$ may represent appropriate prenatal status. We contend that it is appropriate to aim for a preterm selenium concentration which is equivalent to that of breastfed term infants. Whether this will allow preterm infants to compensate for the additional oxidant stress of respiratory support is as yet unknown.

At normal selenium intakes urine is the major route of selenium excretion and it regulates homoeostasis. ${ }^{29}$ As far as is known, this is the first study to evaluate the impact of parenteral nutrition supplementation on urinary selenium. We have shown that urinary selenium in the $\mathrm{PN}+$ selenium group and was 1.5-2 times greater at each of the six weeks and declined with postnatal age in both groups. Smith et $a^{30}$ reported a difference in single void sample urinary selenium $(\mu \mathrm{g} / \mathrm{l})$ from preterm infants between 2 and 6 weeks of age who had a five-fold difference in intake due to the use of selenite supplemented formula.

The implications of these substantial differences in urinary selenium are unclear. The $\mathrm{PN}+$ selenium group may have had adequate selenium concentrations compared with the

Figure 3 Median urinary selenium at each week for unsupplemented (PN-selenium) and supplemented (PN+selenium) preterm infants. 
PN-selenium group; the high urinary concentrations represented excretion of surplus selenium. However, this is not consistent with the changes in plasma and erythrocyte selenium and there is no evidence that plasma selenium plateaus or declines with selenium sufficiency. ${ }^{31}$ An alternative theory is that inorganic selenium, of the form found in parenteral nutrition, is poorly retained compared with the organic selenocystine and selenomethionine found in expressed breast milk and formula, ${ }^{16}$ and thus may be relatively unavailable, with high doses excreted in the urine. Inorganic selenium is primarily used for synthesis of selenocystine in functional seleno-proteins and may not be readily stored. ${ }^{32}$ Finally, the mechanism of plasma selenium transport has yet to be elucidated but in humans it is suggested that inorganic selenium is bound to very low density lipoprotein and low density lipoprotein, ${ }^{33}$ which are low in newborn infants in the first few weeks of life. ${ }^{34}$ It may be that high doses of inorganic selenium overwhelm the transport capacity of the preterm infant and comparatively reduce the bioavailability.

Blood and erythrocyte GSHPx is thought to be a functional marker in adults, in that there is good correlation with whole blood selenium up to a plateau of enzyme activity which is thought to represent sufficiency. ${ }^{35}$ The apparently anomalous rise in GSHPx in the $\mathrm{PN}$-selenium groups is not readily explained. However, others have found erythrocyte GSHPx activity in preterm infants to be inconsistent with adult patterns, ${ }^{15} 30$ and it may not be a good marker of selenium concentrations in the neonatal period. There is some speculation that GSHPx concentrations may be confounded by increased activity on exposure to oxygen $^{19} 36$ and steroids. ${ }^{37}$

We hypothesised that the prevention of selenium deficiency should reduce the incidence of oxygen induced free radical damage in preterm infants (CLD), but the clinical relevance of compromised selenium status in infants and the clinical benefits of achieving adequate concentrations are far from clear. Nevertheless, several studies have reported trends that support the notion that selenium status affects clinical outcome. ${ }^{13-15} 28$ Our study was not designed to address this aspect, but limited data have been included to provide a clinical profile of our population. The sample is obviously too small to assess the impact of selenium supplementation on CLD, and the groups were not matched for this end point. However, the increased incidence of sepsis in the $\mathrm{PN}$-selenium group is interesting as animal studies have suggested that selenium has a role in immunocompetence ${ }^{38}$ and selenium supplementation seems to enhance the immune response in humans. ${ }^{39}$

Several authors have cautioned against higher dose selenium supplementation because of selenium toxicity. ${ }^{13} 1540$ There have been no reports of selenium toxicity in infants and daily intakes of up to $47 \mu \mathrm{g}$ by breastfed infants from high selenium areas in the United States have been reported, with no evidence of selenosis. ${ }^{41}$ Extrapolating from studies of Chinese adults with chronic symptomatic selenosis, it has been estimated that intakes of 130-160 $\mu \mathrm{g} / \mathrm{kg} /$ day would be required to elicit a toxic response in a $6 \mathrm{~kg}$ infant. ${ }^{41}$ The highest individual plasma concentration recorded in the $\mathrm{PN}+$ selenium group was $51 \mu \mathrm{g} / 1$ which is below newborn concentrations reported elsewhere ${ }^{1328}$ and similar to the concentrations of term breastfed infants in this study.

In conclusion, this study suggests that parenteral selenium intakes of $2.8 \mu \mathrm{g} / \mathrm{kg} /$ day improve selenium concentration, but in conjunction with enteral intakes of $1 \cdot 5-2 \cdot 0$ $\mu \mathrm{g} / \mathrm{kg} /$ day from expressed breast milk and formula, respectively, they do not attain the concentrations of healthy breastfed term infants. We suggest supplementation of parenteral nutrition for preterm infants with at least $3 \mu \mathrm{g} / \mathrm{kg} /$ day, but considering the large urinary losses documented, would hesitate to recommend more without further studies of higher doses of different selenium forms. In Australia formulas are not supplemented with selenium and current enteral feeding practices fail to maintain newborn selenium concentration or achieve selenium content similar to that of term breastfed infants. Thus supplementation of formula at least to concentrations found in human milk is recommended. Interestingly, extrapolating from the expressed breast milk selenium concentration measured in this study and a daily intake of $150 \mathrm{ml} / \mathrm{kg}$, the intake from expressed breast milk alone would be $2 \cdot 4$ $\mu \mathrm{g} / \mathrm{kg} /$ day. This is below the parenteral nutrition intake of $2.8 \mu \mathrm{g} / \mathrm{kg} /$ day (albeit it in a different form) that failed to provide term breastfed selenium concentrations. We therefore recommend supplementation of both parenteral nutrition and formulas, but the optimal level and form of supplementation remains unclear. Once this has been determined, a large long term randomised clinical trial is needed to assess the clinical relevance of selenium depletion and the impact of its supplementation on free radical damage and CLD in preterm infants.

We thank the parents for participating in the study, Dr $P$ Marshall, Dr S James, and the nursing staff from the NICU, Flinders Park Medical Centre for assistance with recruitments and samples; Dr I Dreosti and Dr I Record, CSIRO Division of Human Nutrition for use of the AAS; Ms S Taylor for statistical advice; and Mr R Metcalf and Mr M Neumann for help with the manuscript.

1 Lockitch G. Selenium: clinical significance and analytical concepts. Crit Rev Clin Lab Sci 1989; 27: 483-541.

2 Xia Y, Hill KE, Burk RF. Biochemical studies of a selenium-deficient population in China: measurement of selenium, glutathione peroxidase and other oxidant defense indices in blood. F Nutr 1989; 119: 1318-26.

3 Shenkin A, Fell GS, Halls DJ. Selenium and chromium requirements during intravenous nutrition. In: Prasad AS, ed. Essential and toxic trace elements in human health and disease. New York: Alan R Liss, Inc. 1988: 479-88.

$4 \mathrm{Kien}$ CL, Ganther HE. Manifestations of chronic selenium deficiency in a child receiving total parenteral nutrition. Am $\mathcal{F}$ Clin Nutr 1983; 37: 319-28.

5 Brown MR, Cohen HJ, Lyons JM, et al. Proximal muscle weakness and selenium deficiency associated with long term parenteral nutrition. Am $\mathcal{f}$ Clin Nutr 1986; 43: 549-54.

6 Kelly DA, Coe AW, Shenkin A, Lake BD, Walker-Smith pa. Symptomatic selenium deficiency in a child on home parenteral

7 Vinton NE, Dahlstrom KA, Strobel CT, Ament ME. Macrocytosis and pseudoalbinism: manifestations of selenium deficiency. $\mathcal{F}$ Pediatr 1987; 111: 711-17.

8 Kawakubo K, IIda M, Matsumoto T, et al. Progressive encephalopathy in a Crohn's disease patient on long-term 
total parenteral nutrition: possible relationship to selenium deficiency. Postgrad Med ₹ 1994; 70: 215-19. 9 van Rij AM, McKenzie JM, Thomson CD, Robinson MF. Selenium supplementation in total parenteral nutrition. f Parent Ent Nutr 1981; 5: 120-4.

10 Greene HL, Hambidge KM, Schanler R, Tsang RC. Guidelines for the use of vitamins, trace elements, calcium, magnesium, and phosphorus in infants and children receiving total parenteral nutrition: report of the children receiving total parenteral nutrition: report of the Subcommittee on Pediatric Parenteral Nutrient
Requirements from the Committee on Clinical Practice Requirements from the Committee on Clinical Practice
Issues of the American Society for Clinical Nutrition. Issues of the American Society for
Am $\mathcal{F}$ Clin Nutr 1988; 48: $1324-42$.

11 Bayliss PA, Buchanan BE, Hancock RGV, Zlotkin SH Tissue selenium accretion in premature and full-term infants and children. Biol Trace Elem Res 1985; 7: 55-61.

12 Kumpulainen J. Selenium: requirement and supplementation. Acta Paediatr Scand Suppl 1989; 351: 114-17.

13 Lockitch G, Jacobson B, Quigley G, Dison P, Pendray M. Selenium deficiency in low birth weight neonates: an unrecognized problem. F Pediatr 1989; 114: 865-70.

14 Darlow BA, Inder TE, Graham PJ, et al. The relationship of selenium status to respiratory outcome in the very low birth weight infant. Paediatrics 1995; 96: 314-19.

15 Sluis KB, Darlow BA, George PM, Mogridge N, Dolamore BA, Winterbourn CC. Selenium and glutathione peroxidase levels in premature infants in a low selenium com-
munity (Christchurch, New Zealand). Ped Res 1992; 32: munity

16 Kumpulainen J, Salmenperä L, Siimes MA, Koivistoinen P, Lehto J, Perheentupa J. Formula feeding results in lower selenium status than breast-feeding or selenium supplemented formula feeding: a longitudinal study. Am $\mathcal{F}$ Clin Nutr 1987; 45: 49-53.

17 Daniels LA, Gibson RA, Simmer K. Selenium status in term and preterm infants. Proc Nutr Soc 1994; 53: 263A

18 Southorn PA, Powis G. Free radicals in medicine. I. Chemical nature and biologic reactions. Mayo Clin Proc 1988; 63: 381-9.

19 Cross CE, Hasegawa G, Reddy KA, Omaye ST. Enhanced lung toxicity of $\mathrm{O}_{2}$ in selenium-deficient rats. Res Commun Chem Pathol Pharmacol 1977; 16: 695-706.

20 Hawker FH, Ward HE, Stewart PM, Wynne LA, Snitch PJ. Selenium deficiency augments the pulmonary toxic effects of oxygen exposure in the rat. Eur Respir $\mathcal{F} 1993$; 6: of oxygen

21 The Committee of Revision. The United States pharmacopeia: the national formulary. 22th edn. Rockville, MD: The United States Pharmacopoeial Convention, Inc. 1989: 1243

22 Jacobson BE, Lockitch G. Direct determination of selenium in serum by graphite-furnace atomic absorption spectrometry with deuterium background correction and a reduced palladium modifier: age-specific reference ranges. Clin Chem 1988; 34: 709-14.

23 Knowles MB, Brodie KG. Determination of selenium in blood by Zeeman graphite furnace atomic absorption spectrometry using a palladium-ascorbic acid chemical modifier. F Anal Atomic Spectrom 1988; 3: 511-16.
24 Koh TS, Benson TH. Critical re-appraisal of fluorometric method for determination of selenium in biological materials. F Assoc Off Anal Chem 1983; 66: 918-26.

25 Hojo Y. Single-void urine selenium level expressed in terms of creatinine content as an effective and convenient indicator of human selenium status. Bull Environ Contam Toxicol 1982; 29: 37-42.

26 Beutler E. Red cell metabolism: a manual of biochemical methods. 4th edn. New York: Churchill Livingstone, 1986: methods

27 Levander OA. Considerations on the assessment of selenium status. Fed Proc 1985; 44: 2579-583.

28 Huston RK, Jelen BJ, Vidgoff J. Selenium supplementation in low-birthweight premature infants: relationship to trace metals and antioxidant enzymes. $\mathcal{F}$ Parent Ent Nutr 1991 15: 556-9.

29 Alaejos MS, Romero CD. Urinary selenium concentrations Clin Chem 1993; 39: 2040-52.

30 Smith AM, Chan GM, Moyer-Mileur LJ, Johnson CE Gardner BR. Selenium status of preterm infants fed human milk, preterm formula, or seleniumsupplemented preterm formula. $\mathcal{F}$ Pediatr 1991; 119: 429-33.

31 Kumpulainen J, Salmenperä L, Siimes MA, Koivistoinen P Perheentupa J. Selenium status of exclusively breast-fed infants as influenced by maternal organic or inorganic infants as influenced by maternal organic or inorganic 829-35.

32 Janghorbani M, Martin RF, Kasper LJ, Sun XF, Young VR. The selenite-exchangeable metabolic pool in humans: a new concept for the assessment of selenium status. Am f Clin Nutr 1990; 51: 670-7.

33 Bopp BA, Sonders RC, Kesterson JW. Metabolic fate of selected selenium compounds in laboratory animals and man. Drug Metab Rev 1982; 13: 271-318.

34 Van Biervliet JP, Rosseneu M, Bury J, Caster H, Stul MS, Lamote R. Apolipoprotein and lipid composition of plasma lipoproteins in neonates during the first month of life. Ped Res 1986; 20: 324-8.

35 Dreosti IE. Selenium. F Food Nutr 1986; 43: 60-78.

36 Jornot L, Junod AF. Differential regulation of glutathione peroxidase by selenomethionine and hyperoxia in endothelial cells. Biochem $\mathcal{F}$ 1995; 306: 581-7.

37 Ward KP, Arthur JR, Russell G, Aggett PJ. Blood selenium content and glutathione peroxidase activity in children with cystic fibrosis, coeliac disease, asthma, and epilepsy. with cystic fibrosis, coeliac diseas
Eur $\mathcal{F}$ Pediatr 1984; 142: $21-4$.

38 Turner RJ, Finch JM. Selenium and the immune response. Proc Nutr Soc 1991; 50: 275-85.

39 Kiremidjian-Schumacher L, Roy M, Wishe HI, Cohen MW, Stotzky G. Supplementation with selenium and human immune cell functions: II. Effect on cytotoxic lymphocytes and natural killer cells. Biol Trace Elem Res 1994; 41: 115-28.

40 van Caillie-Bertrand $M$, Degenhart HJ, Fernandes J. Selenium status of infants on nutritional support. Acta Paediatr Scand 1984; 73: 816-19.

41 Levander OA. Upper limit of selenium in infant formulas. f Nutr 1989; 119: 1869-72. 